\title{
The emergence of business model for digital innovation projects without predetermined usage and market potential
}

\author{
Katerina Antonopoulou \\ IESE Business School \\ Kantonopoulou@iese.edu
}

\author{
Joe Nandhakumar \\ Warwick Business School \\ Joe.Nandhakumar@wbs.ac.uk
}

\author{
Christos Begkos \\ Alliance Manchester Business School \\ Christos.Begkos@manchester.ac.uk
}

\begin{abstract}
In this paper we explore the emergence of business model for digital innovation projects without predetermined usage and uncertain market potential. We studied a firm, which was producing and launching digital platforms for managing organizational operations. Drawing on a case study of developing this digital platform, we identified three recurring calculative and narrative practices: ideating; concocting; aligning. We argue that through these practices various epistemic objects (which we call 'learning catalogue') were enacted representing the emerging consensus of the usage and market potential for the digital innovation under development, and simultaneously enabling actors to create new knowledge of what was not known. This dynamic learning catalogue represented the constantly evolving implicit business model for value generation. We offer significant contributions to business model studies in the context of digital innovation projects, and implications for the transformation of the contextual and technical uncertainty into calculable risk.
\end{abstract}

\section{Introduction}

Digital technologies offer numerous opportunities for digital project managers by revolutionizing the ways to create and capture value. The particular architecture of digital technology products [36] and their ever-increasing incorporation into a growing number of products and services facilitate new business models [3]. However, digital project managers often find it challenging to formulate a business model for their digital innovation projects as they are surrounded with technical and contextual uncertainty, which makes at the same time the existing views of business models for such projects no longer relevant [32], [36], [12], [11], [17]. For example,
Youtube's business model had been initially criticized as non-existent or nonviable. Nevertheless, it has become the biggest video platform and it is still trying to figure out a business model for sustaining itself. Such a setting is an intriguing example of digital innovation projects for which the developers and managers struggle to develop a business model and it is even more fascinating in the case of start-ups which aim to reconstruct market boundaries while they are striving to predetermine the potential uses of their innovation and assess the market potential.

The concept of business model associated with innovative technological projects has attracted many academics but there is still less discussion in the digital innovation literature. Development of digital innovation projects is surrounded with uncertainty around the definition of, and the relations between, business model components [18], [11]. The developers have limited understanding of the usefulness manifested in the new digital technology projects under development and how to assess the market potential and the revenue streams as a crucial step towards a business model. In this paper, we seek to address this issue by exploring the emergence of a business model for digital innovation project through the calculative and narrative practices of the actors involved in the innovation process.

We studied a start up in England for two years, which was producing and launching digital platforms based on virtual reality utilized for training, learning, human resources and overall organizational operations. Although the company grew rapidly, we were impressed by their profitable performance without having an explicit business model. Each digital product was considered as a project with high uncertainty since the project team was aware of the suspiciousness of the market for such innovative digital products. Hence, the constantly evolving perceptions for the design of each digital project, and the accumulation of digital and physical capabilities were changing the perceptions of digital project managers about the potential market, the 
revenue streams and the eventual offering increasing the uncertainty.

Based on our analysis of an in-depth, qualitative study, we seek to understand the emergence, change and stability of events through their sequential evolution [20] and we explore the emergence of business model for digital innovation projects without predetermined usage and uncertain market potential. We are able to offer two significant contributions. First, we contribute to prior business model studies by developing a better understanding of the emergence of an implicit business model in the context of digital innovation projects with uncertain usage and market potential. Second, we provide novel insights regarding the implications of this dynamic process for the transformation of uncertainty into calculable risk through the enactment of a learning catalogue.

\section{Business model and Digital innovation}

Academics as well as practitioners have discussed the notion of "business model", however it is often acknowledged as underdeveloped concept [22], [12], [15]. Zott et al. [37], have highlighted that business models "have yet to develop a common and widely accepted language that would allow researchers who examine the business model construct through different lenses to draw effectively on the work of others" [37], thus business models have often been contested in novel or fairly new contexts such as digital innovations [36], [1].

Within the existing literature the development of a business model is seen as static description constituted by the inclusions of different components or elements [1], [31], [2], [11] and it is often considered as a description that exists beyond the firm. In fact, business model has been discussed primarily in relation to what the components of a business model are [18], [1] and how a business model relates to the creation of value and firm performance in the context of ebusiness [15], [27], [28], [30], [23], [37]. Other studies in marketing and strategy have focused on the role of the business model and its components in relation to competitive advantage [2], [12], [8], [31]. Overall, there is a breadth of perspectives in many different contexts, with different approaches creating a divergence of views rather than a common ground [18], [1], [37]. This has primed a research interest in how a greater conceptual coherence regarding what constitutes a business model can be brought about [18], and how diverse insights resulting from recent research and studies might be integrated [1].
One alternative view comes from Doganova and Eyquem-Renault [14], who draw attention to how the business model, as a calculative and narrative device, helps to explain what value is created and shared, providing a "synthetic explanation of complex processes" and conveying a "coherent portrait to an audience". In this context the business model as well as its "building blocks" are articulated longitudinally. However, there is lack of understanding of how this is can be a dynamic process to provide an explanation of the complex performative actions of digital project managers while being surrounded with uncertainty concerning the use of their digital innovations and the market potential.

The application of traditional approaches, on a step by step basis such as STOF model [38] or a snapshot description such as Canvas model, [27] obscure the formulation of a business model for digitals innovations for two reasons. First, the "prospective" [14] but also the "equivocal" [5] nature of such technologies and the technical uncertainty resulting from the loose coupled digital and physical capabilities [36] (p. 725) make the development of a business model misleading. Hence, those participating in the formulation of the business model are engaged in a struggle to manage the uncertainty of the innovation process [21], [34], [35] while also assessing a continuously and often rapidly changing market potential. Thus, uncertainty, considered as the unknown and quantitatively unpredictable events [13], challenges the formulation of a business model with incomplete and reliable information. It is a key motivation behind the study presented in this paper to research how the process associated with the emergence of business model can also act as a mechanism to transform the technical and market uncertainty into risk. Risk is considered as the known unknown, thus it is tangible making the calculation possible by digital project managers.

The second reason is that the potential of digital innovations to transform the production and use contexts [36] obscures the process to create and capture value until the commercialization [11], and makes the formulation of an upfront business model illusive. Within this context, digital project managers involved in the development of such innovative digital products do not have a fixed or predetermined idea for their innovations while they attempt to reconstruct market boundaries and, in turn, prospective customers and users struggle to understand their contribution and usefulness. Hence, digital project managers are in a constant attempt to understand their digital value proposition, the target audience but also to determine 
an appropriate revenue model. To date, most digital ventures have a try-it-and-see-what-happens approach and they focus around serendipity. This has primed a research interest in the underlying process of business model development [11], which can give rise to an emerging and constantly transforming business model.

\section{Research Approach and Empirical Setting}

We conducted an in-depth, qualitative study at ASolutions (pseudonym) from October 2012 and August 2013. A-Solutions has mission to lead the revolution in 3D training, visualisation and interactive simulation, enabling their potential clients to reach their full potential for a range of organizational operations such as training, learning, marketing or even advertising. During the period of the study, a small team of programmers and artists constituted the project team, with experience in 3D environments as well as knowledge of game design principles, human computer interfaces and artificial intelligence. Their ambition was to create a new segment of digital platforms industry with novel usage for different markets. They were focusing on how digital platforms can be used to help firms to train and educate their employees so as to dynamically develop, assemble, test, deploy, and iterate operations and services.

Although the company was growing rapidly, we were impressed by their profitable performance without having an explicit business model. The design of the digital products was constantly changing due to the efforts of A-Solution's project managers to probe and sense possible usages and market opportunities.

\section{Data collection and analysis}

Data collection involved semi-structured interviews, participating in business development activities (e.g. business strategy development for ASolutions), observation of the design process, and collecting documents and historical data, between October 2012 and August 2013. We have conducted fifteen semi-structured interviews with project managers of A-Solutions including, founders, designers, programmers, software engineers, software artists, project leaders and instructional designers. The interviews lasted on average around $45 \mathrm{mins}$ and were voice recorded and transcribed. In addition to formal interviews we have also had several informal conversations with participants and email exchanges. Thus, one of the authors cooperated with the project managers of the company for a market research. Last, we have also collected historical data and documents from the companies, such as research reports, conference papers and presentations, commercial reports, financial statements published material such as articles on press release concerning the company, their platforms and their business strategy and vision.

The analysis of the empirical material (interview transcripts, observation notes, documents and the other material from the field study) collected at A-Solutions focused on a three-step approach. First, we focused on identifying and highlighting extracts relating to decisions made during the innovation process of a digital project (Gear - pseudonym) concerning the product specifications, the value proposition, the potential market and the revenue streams. At this stage, we acknowledge the difficulty of analysing process data but it was crucial for the aim of the study to make sense of practices and activities [19]. Then, in the second step, we worked iteratively back and forth throughout the innovation process and our empirical data and we wrote a number of vignettes [24] focused on the description of these decisions. Through these vignettes we were able to identify the recurrence of local practices. Last, in the third step, we conducted theme analysis of the key practices and we were able to identify three recurrent practices, which we named: ideating, concocting and aligning.

For illustrative purposes, Table 1 provides examples of some of these vignettes throughout the innovation process and the analytical themes that emerged from our analysis.

\section{The enactment of a learning catalogue}

In 2012, the founders of A-Solutions had an idea for a digital platform that could help users experience car driving in a big city, the countryside and in different conditions or go just for a joy ride. At the stage of idea generation, the concept was vague and it was described as a "rather simple car game" (Alex, graphics designer). During consecutive meetings they tried to narrow down the initial idea, justify the usefulness of the platform and make a decision regarding the continuation of the project and the undertaking of further research. The project managers of the company were aware the existence of simulation products but they considered their project distinct with the aim to be implemented for workplace use rather than as a simulation of multiple scenarios for air force or a video game console for entertainment. Andy, project manager at A-Solutions, claimed: 
"There is a huge need to get an understanding why the game is beneficial and to bring forth strong reasons for which it induces a change to employ game mechanics in the workplace and daily lives. Simulations are often less fun because they are based on more extreme context. Gear is a learning and training solution. It is also fun and interactive, and provides opportunities for failure to happen in a safe environment related to a performance outcome."

At this stage, the idea was very generic and there was neither an identified gap in the market nor an enquiry from a specific interested costumer. At the same time, as the aim of the platform was vague this had an impact on the digital and physical features of the project interrelated to uncertainties about its perceived usefulness to the potential customers. However, an important decision was made since it had as a result the continuation of the project and the surfacing of the need for the development of an initial business model. Their decision to develop a car driving platform rather than any other vehicle platform was mostly about 'inspiration', 'vision', 'passion', and 'imagination'. Thus, the concept for the project was reflecting their concerns about their value proposition. They were considering the platform would offer 'novelty' and 'creativeness' across different markets where the cars are used such as automotive companies, police, fire services, healthcare (ambulances) or even the army. However there was one key issue; their value proposition could create misconceptions regarding the usefulness and effectiveness of the digital platform since the potential customers could easily misconceive the potential of the platform or its benefits in the workplace. Nevertheless, the project managers had a list of ideas around the project. Robert, content and branding consultant, claimed:

"what we do is to present between us the information and the research we 've done. In this space rather doing a full business model that is 50 pages you can do it in 2 pages with your assumptions and as we go on and we are finding out what is the product that we are selling we can switch. That is what we do with our business documents. [...] So that's mine and our interpretation of a good business model, keep it short and sweet and very flexible because when you are going to new spaces when you try to make a product for a new market you do not know all the answers"(Robert, content and branding consultant).

When the project managers of the company initiated the development, they were attempting to identify the most appropriate features for the platform. Since the company was new and small there were budget constraints and as such the project managers of the company were in a constant negotiation as for the features of the platform and reasons they were deemed valuable and how these would "provide added capabilities and increased realism to this enjoyable platform" as the Mark, the development director claimed, and then he continued:

"the problem is that the market is fairly polarized and we get people very familiar with video games that they want amazing graphics generally $3 D$ for very small budget or we find people in that markets very naive, they want to be involved because they can see that there is a draw but maybe their experience is limited to playing games when they were a child or they still got a latent suspicion of them." (Mark, development director)

For this reason the project managers of A-Solutions were keeping a catalogue with the features of the 'Gear' project and how their incorporation would benefit the platform. This catalogue was including the features they had used to accomplish each project task, their knowledge about the context and purpose of the project associated with the features facilitating this purpose and their perceptions concerning the impact of the features to the usefulness of the overall project. As the development process was evolving the project managers of the company were also attempting to meet potential customers. Robert, the content and branding consultant, noted:

"the naive customer is nervous when we are introducing a platform that is for business because as soon as we start introducing elements that are very video game like, we can see their recalls so we are trying in our way to pull the bate of business more into using the games technology. So when it is time to sell it we struggle with the words game and serious game, simulator and we have to take into account that you have got people that like games and they wonder how a game can be serious. So a lot of time is a gentle exercise and sometimes we even avoid the word game so we talk about fidelity of graphics, connectivity etc. We are just trying to avoid these hot subjects when we are talking to our customers" (Robert, content and branding consultant)

Nevertheless, the uncertainty for the project managers of A-Solutions was high. Although this market for platforms was fairly new and uncontested the vague market potential and the absence of demand 
was considered as a high risk but at the same time as an opportunity for rapid growth and profitability. Consequently, the project managers of the company were in a constant trial to formulate a business model but this was impossible with the use of traditional approaches. The project managers were trying to figure the best practices to reduce their uncertainty and maximize their potential profits. As such, they were unconsciously using the emerging knowledge of their practices to transform it into useful information in terms of relative advantage intertwined with economic profitability, low initial cost, reduction in discomfort and savings in time and effort. As Josh, the CEO of ASolutions, mentioned:

"We use very traditional strategies to assess the value of the product. It is dependent on the type of the game, the quantity of content, the desired quality and the used technology ". He continued explaining " Gear has an 180 degree, spherical screen, 180 deg horizontal FOV with 35 deg vertical FOV, 6 or 7 million pixel options available, 220 degree horizontal and 65 deg vertical FOV options, renders interior of a vehicle on the screen - truly making you feel you are inside that vehicle. To be honest we are trying to sell it to military but we can turn it into a boat without problem, meaning you can replicate several vehicles or several variations of vehicle in one unit and high frequency, low amplitude motion as standard operating in the $3 \mathrm{~Hz}$ to $100+\mathrm{Hz}$ range. It is a multilingual platform that supports different traffic rules and driving modes. It has navigation tools and allows you view an extra range of gauges as you drive. We can keep the price low and still make a margin this is what we think" (Josh, CEO)

The above account of empirical findings shows how A-Solutions was able to develop a digital platform although the uncertainty about the usage of the digital product and the lack of a clear market potential. This was a highly dynamic process with repeating practices. Table 2 presents some illustrative narrative vignettes in association with the stages of the innovation process within which the business model was being constantly formulated through the practices that repeatedly occurred.

\begin{tabular}{|c|c|c|}
\hline $\begin{array}{c}\text { Stages of } \\
\text { innovation } \\
\text { process }\end{array}$ & Narrative Vignettes & $\begin{array}{c}\text { Narrative } \\
\text { and } \\
\text { calculative } \\
\text { practices }\end{array}$ \\
\hline $\begin{array}{c}\text { Idea } \\
\text { generation }\end{array}$ & $\begin{array}{l}\text { "Although these educational efforts can be effective, the cost for training is high } \\
\text { but the effectiveness limited since they do not involve "hands-on" skill } \\
\text { development and first-hand experience" } \\
\text { "Powerful input device, imagine your entire body being immersed, the user is } \\
\text { accustomed to manipulating the real world" } \\
\text { "Displaying information from the engine management software, including } \\
\text { exhaust and water temperature, oil pressure, G-force and turbo boost but also } \\
\text { functions as a lap timer" } \\
\text { "Trends in the automotive industry have followed a similar pattern over the last } \\
\text { few years; promoting safety and reducing carbon footprints have been prominent } \\
\text { in manufacturers" minds but performance still reigns supreme." }\end{array}$ & $\begin{array}{l}\text { Ideating } \\
\text { Ideating } \\
\text { Aligning }\end{array}$ \\
\hline Development & $\begin{array}{l}\text { "If the game runs too slowly, we reduce the number of objects to improve } \\
\text { performance, which in turn affects the realistic settings" } \\
\text { "We estimated the number of users were going to buy it, the number of previous } \\
\text { platforms have sold within the market and again the role o game mechanics and if } \\
\text { there's something new or more established and if we had to buy a plugin" } \\
\text { "So even if you spend a bit more money (for features) you gain a lot more value } \\
\text { from your cost. You get a little ROI but also you have your human capital" }\end{array}$ & $\begin{array}{l}\text { Concocting } \\
\text { Aligning } \\
\text { Concocting }\end{array}$ \\
\hline
\end{tabular}




\begin{tabular}{|l|l|l|}
\hline Marketization & $\begin{array}{l}\text { "We use very traditional strategies to assess the value of the product. It is } \\
\text { dependent on the type of the game, the quantity of content, the desired quality and } \\
\text { the used technology" } \\
\text { "Storing all the driving data including lap times and the updated product could } \\
\text { include gamefication techniques that introduce a virtual element to the real world } \\
\text { with direct links to social media" } \\
\text { "180 degree, spherical screen, } 180 \text { deg. horizontal FOV with } 35 \text { deg. vertical } \\
\text { FOV, } 6 \text { or } 7 \text { million pixel options available, } 220 \text { degree horizontal and } 65 \text { deg. } \\
\text { vertical FOV options, renders interior of any vehicle on the screen - truly making } \\
\text { you feel you are inside that vehicle, meaning you can replicate several vehicles or } \\
\text { several variations of vehicle in one unit and high frequency, low amplitude } \\
\text { motion as standard operating in the } 3 \mathrm{~Hz} \text { to } 100+\mathrm{Hz} \text { range" }\end{array}$ & Concocting \\
\hline
\end{tabular}

Table 1. Illustrative narrative vignettes

\section{Analytical Overview}

We observed from our analysis the project managers of A-Solutions were in a constant attempt to envision how a digital platform could be valuable for other firms across different market sectors. Hence, they were visually approaching the environment outside the firm attempting to envision how they could create demand for a digital platform that would substitute traditional approaches. We refer to this practice as platform ideating (depicted under a. in Figure 1). In addition, we observed that there was an on-going dissonance among digital project managers related to the physical and digital characteristics of the platform. Throughout these contestations around the relative importance of the features, knowledge about the platform and its usefulness to the potential users was emerging and was accumulated with the knowledge that was emerging from ideating practice. This point to the second emerging practice we observed: concocting (depicted under $b$. in Figure 1). Last, we observed that throughout the innovation process the project managers were approaching potential customers to unlock demand and align the unprecedented usefulness of the digital platform with entrepreneurial hurdles. We refer to this practice as aligning (depicted under b. in Figure 1). The knowledge also derived out of aligning practice was also accumulated with the knowledge emerging out of the ideating and concocting practices.

We call these practices as narrative and calculative because their role is twofold. On the one hand the project managers were explaining or interpreting their ideas for the project, the context or the perceptions of the potential customers through narrated accounts and on the other hand they were attempting to calculate the cost of the project, the returns on investment or how they could manage the development process under cost and time pressures. What we want to highlight from the above account is that the project managers of A-Solutions did not have an explicit business model due to the distinct nature of their digital project allowing unexpected and almost unlimited combinations of physical and digital features [36]. Along with the aim to reconstruct market boundaries, the project managers were attempting to manage their uncertainty. Hence, they were in constant trial to weave together their knowledge coming out from their ideas for the digital platform, the features of the platform and their attempts to approach potential customers. These observations stimulated us to generate a way of thinking about the emergence of business model, and to develop a model depicting the practices which condition the enactment of epistemic objects [29], [9].

In fact, our data analysis showed that several conceptual objects such as PowerPoint slides of value stories, brainstorming documents for the physical and digital making of the project, logs (online) of experiences and materialisation of the objectives as well as market research documents were enacted through the narrative and calculative practices. These objects served more like 'epistemic objects' [9], and their 'lack and incompleteness' [16] (p. 9) were stimulating the creation of new knowledge, while representing the emerging agreements and decisions 
of the project managers for the usage and market potential. We call this collection of incomplete objects 'learning catalogue', thus the knowledge, which is embodied, is not hierarchically listed but descriptive and cumulative.

This leaning catalogue is considered as 'possession of knowledge' [6], embedded in the recurring practices of the actors. Hence, it contained all the known knowledge about the uncertain and non-predetermined project, providing consensus about the market potential, the revenue streams and the value proposition. This learning catalogue is seen as the knowledge emerging from the performative practices of the actors involved in the innovation process of the digital project and it is the source for the creation of new ideas and knowledge throughout the innovation process.

Our analysis shows that this was a dynamic process and that the emerging consensus served as an implicit business model for value generation including the accumulated knowledge from the different stages of the innovation process. The process is recursive in the sense that, as illustrated in the case findings, the project managers seem to reflexively draw on the knowledge embedded in the learning catalogue and the consensus about the market potential, the revenue streams and the value proposition. If successful, the learning catalogue serves the formulation of an implicit business model that becomes a connective entity that keep the emerging learning embedded in the recurring calculative and narrative practices bounded together. Figure 1 summarizes the dynamic process by which the learning catalogue is enacted and serves as an implicit business model for value generation for a digital innovation project.

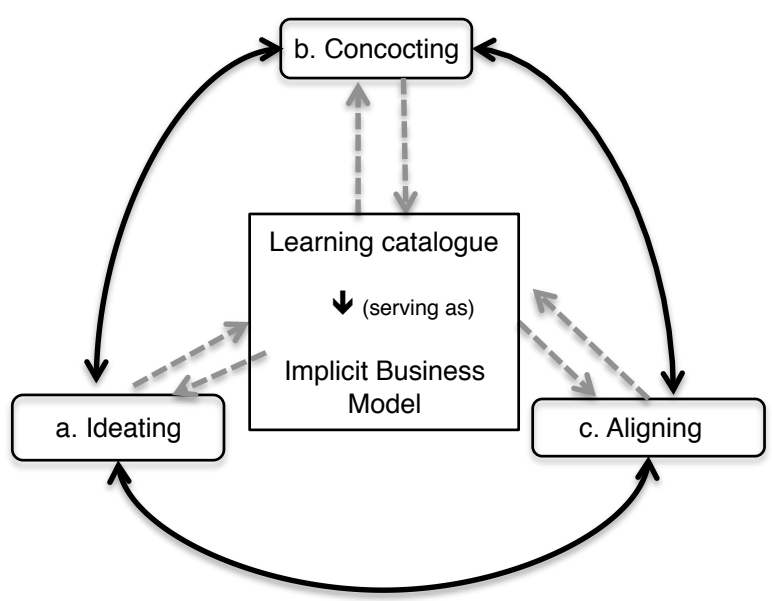

Figure 1: The calculative and narrative practices and the business model emergence

\section{Discussion and Implications}

Unlike much of existing views of the business model in which it is formulated up-front and in a static way [1], [31], [27], [18], [38] or on a step by step approach [38], in the conceptualization, we propose from our study that three practices are coming together giving rise to accumulated knowledge with potential for creation of new knowledge over time. Through these practices the various epistemic objects are enacted and the knowledge is constantly accumulated. Seen in this way, the learning catalogue represents an implicit business model for value generation. This implicit business model emerges and evolves as new knowledge is generated for a digital innovation project without predetermined usage and market potential. In addition, from our empirical findings, we are able to show that the emergence of a business model is possible even with uncertainty about the usage of a digital innovation and lack of clear market potential since the knowledge coming out of the narrative and calculative practices plays a crucial role in making visible the components/elements of an evolving business model. As the process unfolds, the consensus becomes more clear and stabilized due to the generation of new knowledge.

Second, this process brings clarity and gradual stability to the emergence of a business model and has implications for managing the uncertainty and the tension between framing and overflowing [7] inherent to the complex nature of a digital project. In this way, the technical and contextual uncertainty is being transformed into known uncertainty, which is calculable through stabilized rationales emerging out of the uncertainty. By describing and theorizing the emergence of an implicit business model when there is market and usage uncertainty, we also bring clarity to some of the insights developed by Doganova and Eyquem-Renault [14] on how a business model can be seen as calculative and narrative device. Throughout the process the project managers are able to assess and re-assess their possessed knowledge [26], [6], [33] and obtain "the knowledge required to produce and stabilise" [25]. The dissonance among those involved in the formulation of business model shows the enactment of a learning catalogue, which plays an epistemic role [16] to exploit the existing ambiguity in a way that accounts for both emergence and stability. Hence, such a conceptualization of the business model can provide useful insights to those interested to provide a heuristic "template" [4] that transforms the uncertainty into calculable risk through a constant evolving business model. 
Finally, the insights gained from our study also have implications for the practitioners who face the challenge of formulating a business model for digital innovations and managing their development and commercialization in highly dynamic and complex conditions. Our study shows a dynamic view of an implicit business model and how the knowledge coming out of the recurring practices, which take place within the innovation process, is a step towards into transforming the uncertainty into calculable risk.

Our research also comes with limitations. First, the study builds on a single case study, where the type of insights generated should be seen as generally applicable to other digital innovation projects without predetermined usage and market. Comparative studies may enable cross-comparison to discover possible variation in how business model emerges in different settings. Second, further work should clarify how the dissonance between the actors is managed especially with different status or power.

\section{References}

[1] M. M. Al-Debei, and D. Avison, "Developing a unified framework of the business model concept", European Journal of Information Systems, 2010, 19(3), pp. 359-376.

[2] R. Amit and C. Zott, "Value creation in e-business". Strategic management journal, 2001, 22(6-7), pp. 493-520.

[3] C. Baden-Fuller and S. Haefliger, "Business models and technological innovation". Long range planning, 2013, 46(6), pp.419-426.

[4] C. Baden-Fuller and S. Winter, "Replicating knowledge practices: Principles or templates". 2007, Working paper, Cass Business School, City University, London, UK.

[5] N. Berente, S. Hansen, J.C. Pike, and P. J. Bateman (2011). "Arguing the value of virtual worlds: patterns of discursive sensemaking of an innovative technology". MIS Quarterly, 2011, 35(3), pp. 685-709.

[6] F. Blackler, "Knowledge, Knowledge Work and Organisations: An Overview and Interpretation". Organisation Studies, 1995, 16(6): pp. 1201-41.

[7] M. Callon, "An essay on framing and overflowing: economic externalities revisited by sociology."The Sociological Review, 1998, 46(S1), pp.244-269.

[8] F. Carton, J. Hedman, J. Damsgaard, K. T.Tan, and J. McCarthy, "Towards a Framework for the Evaluation of Mobile Payments Integration”. 2010, Paper presented at the 5th European Conference on Information Management and Evaluation.
[9] K.K Cetina, "Sociality with objects: Social relations in postsocial knowledge societies". Theory, culture \& society, 1997, 14(4), pp.1-30.

[10] H. Chesbrough, "Why companies should have open business models". MIT Sloan management review, 2012, 48(2).

[11] H. Chesbrough, "Open business models. How to thrive in the new innovation landscape", Boston: Harvard Business School,2013.

[12] H. Chesbrough and R. S. Rosenbloom, "The role of the business model in capturing value from innovation: evidence from Xerox Corporation's technology spin-off companies". Industrial and Corporate Change, 2002, 11(3), pp. 529-555.

[13] J. F. Cox and J. H. Blackstone, The Educational Society for Resource Management (ninth ed), Viginia, USA, 1998.

[14] L. Doganova and M. Eyquem-Renault "What do business models do?: Innovation devices in technology entrepreneurship". Research Policy, 2009, 38(10), pp.15591570 .

[15] M. Dubosson-Torbay, A. Osterwalder and Y. Pigneur "E-business model design, classification, and measurements". Thunderbird International Business Review, 2002, 44(1), pp. 5-23.

[16] B. Ewenstein and J. Whyte, "Knowledge practices in design: the role of visual representations asepistemic objects" Organization Studies, 2009, 30(1), pp.07-30.

[17] G. Hamel "Leading the revolution". Boston: Harvard Business School Press, 2000.

[18] J. Hedman and T. Kalling "The business model concept: theoretical underpinnings and empirical illustrations". European Journal of Information Systems, 2003, 12(1), pp. 49-59.

[19] A. Langley, "Strategies for theorizing from process data". Academy of Management review, 1999, 24(4), pp. 691-710.

[20] A. Langley, C. Smallman, H. Tsoukas and A. H. Van de Ven, "Process studies of change in organization and management: unveiling temporality, activity, and flow". Academy of Management Journal, 2013, 56(1), pp.1-13.

[21] K. Lyytinen and J. Damsgaard, "What's Wrong with the Diffusion of Innovation Theory?", Diffusing Software Product and Process Innovations, 2001, Vol. 59, pp. 173190.

[22] J. Magretta, "Why business models matter". Harvard Business Review, 2002, 80(5), pp. 86-92. 
[23] T. Malone, P.Weill, R. Lai, V. D'Urso, G. Herman,T. Apel, and S. Woerner "Do some business models perform better than others?", MPRA Paper no. 4752, 2006.

[24] M.B. Miles and A. M. Huberman, "An expanded Soucrebook - Qualitative Data Analysis”,SAGE, 1994.

[25] F. Muniesa, Y. Millo, and M. Callon,"An introduction to market devices". The sociological review, 2007, 55(s2), pp. 1-12.

[26] S. Newell, M. Bresnen, L. Edelman, H. Scarbrough, and J. Swan, "Sharing knowledge across projects limits to ICT-led project review practices". Management Learning, 2006, 37(2), pp.167-185.

[27] A. Osterwalder and Y. Pigneur, "An eBusiness model ontology for modeling eBusiness", BLED Proceedings, 2002.

[28] M. A. Rappa "The utility business model and the future of computing services". IBM Systems Journal, 2004, 43(1), pp. 32-42.

[29] H.J Rheinberger, "Toward a history of epistemic things: Synthesizing proteins in the test tube", Writing Science, 1997.

[30] S. M. Shafer, H. J. Smith and J.C Linder, "The power of business models". Business horizons, 2005, 48(3), pp. 199-207.

[31] D. J. Teece. "Business Models, Business Strategy and Innovation”. Long Range Planning, 2010, 43(2-3), pp. 172194.

[32] M. Tripsas, "Technology, identity, and inertia through the lens of 'the digital photography company". Organization science, 2009, 20(2), pp. 441-460.

[33] H. Tsoukas, "The Firm as a Distributed Knowledge System: A Constructionist Approach". Strategic Management Journal 1996, 17, pp. 11-25.

[34] I. Tuomi, "Networks of innovation: Change the meaning in the age of the internet." Oxford University Press, Oxford, 2002.

[35] A. H. Van de Ven, "Running in packs to develop knowledge-intensive technologies". Mis Quarterly, 2005, pp. 365-377.

[36]Y. Yoo, O. Henfridsson, O. and K. Lyytinen, "Research Commentary-The New Organizing Logic of Digital Innovation: An Agenda for Information Systems Research”. Information Systems Research, 2010, 21(4), pp. 724-735. doi: 10.1287/isre.1100.0322.

[37] C. Zott, R. Amit and L. Massa, "The business model: recent developments and future research". Journal of Management, 2011, 37(4), pp. 1019-1042.
[38] H. Bouwman, E. Faber, T. Haaker, B. Kijl, and M. De Reuver,"Conceptualizing the STOF model. In Mobile service innovation and business models" 2008, pp. 31-70. 